دراسة الامراضية الخلوية لفيروس جدري الاجاج باستخدام اختبار إنزيم البيروكسيد المناعي و صبغة الاكريدين البرتقالية

حارث محمد ابراهيم الحيالي عايد بجعي الزغيبي سعاد عبد الكريم

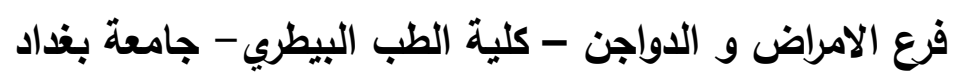

\title{
الخلاصة
}

في هذه الدراسة تم حقن فايروس جدري الدجاج المعزول محلياً في الغشاء اللقانقي المشيمي لاجنة

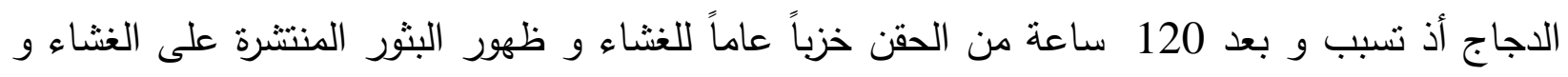

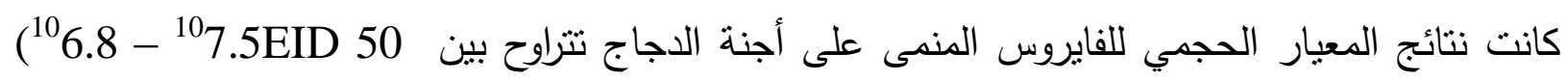
(0.1 ml) ـ ولدراسة تاثير الفايروس في خلايا الزرع النسيجي استخدم اختبار أنزيم البيروكسيد المناعي و

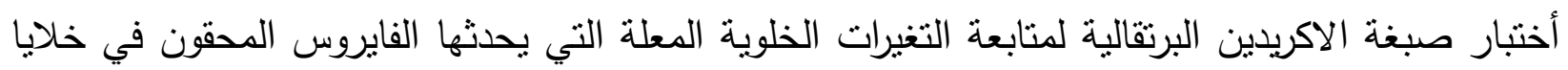
الارومات الليفية بعد 96, 72, 48, 24 ساعة من الاصابة ـ فقد لوحظت الاجسام الاشتمالية الهيولية

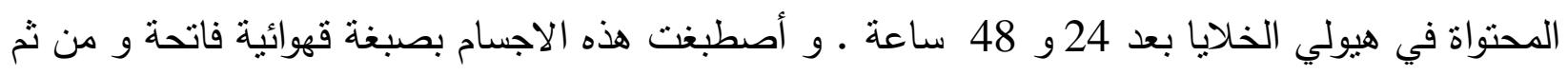
غامقة عند معاملتها بأضداد الفايروس المعاملة بانزيم البيروكسيد المناعي و تطابقت هذئ هذه النتائج مع نتائج

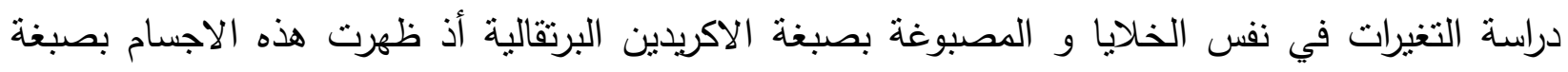

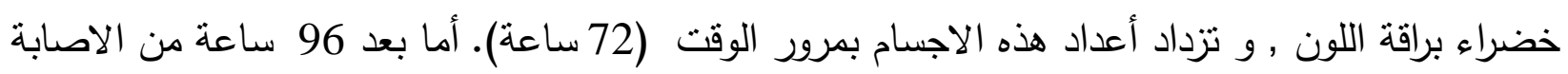

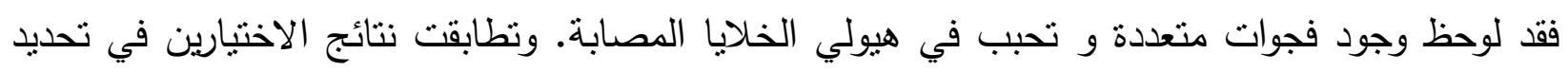
مواقع مستضدات فايروس الجدري في شكلها و زمن ظهوردها.

\section{Cytopathogenicity studied of fowl pox virus by using indirect immunoperoxidase and acridine orange tests .}

Harith M. AL-Hyali, Aied B. AL-Zughaibi and Suad Abdulkarim.

Department of Pathology and Poultry Disease, Collage of Veterinary Medicine , University of Baghdad - Baghdad - Iraq •

\section{Summary}

Locally isolated fowl pox virus was inoculated on chorioallantoic membrane of chick embryos, leads to the appearances of odema and pocks lesion on the membrane , 120 hours post inoculation. Virus assay showed that the infectivity titer were ${ }^{10} 6.8$ to ${ }^{10} 7.5$ EID50/0.1 ml in embryonated chicken eggs. Monolayer tissue cultures of chick embryo fibroblast cells infected with fowl pox virus were 
examined by acridine orange staining and indirect immunoperoxidase test to study the cytopathogenic effects of the virus . The most striking cytoplasmic changes observed was the presence of the intracytoplasmic inclusions at 24-48 hours post inoculation, numerous inclusions were clearly seen at $72 \mathrm{hr}$. P.I.in addition to cytoplasmic vaculation and granulation were clearly seen at $96 \mathrm{hr}$. P.I. These changes stained brilliant green with acridine orange and dark brown staining with immunoperoxidase . Both tests demonstrated the localization of pox virus antigens in infected cells at same intervals.

\section{المقدمة}

مرض جدري الدجاج من الامراض الوبائية التي تصيب الدجاج وفي مختلف الاعمار مسبباً بثور في

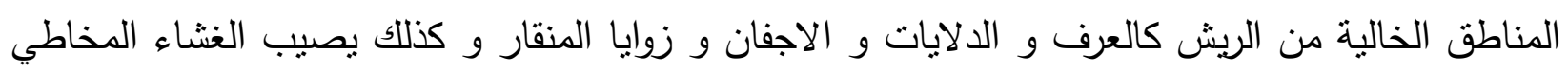

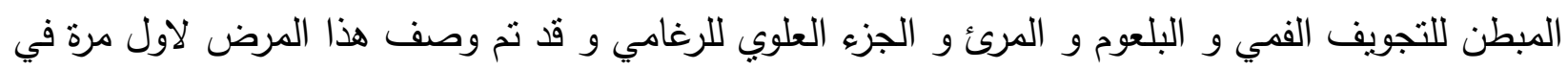
القطر سنة 1975 و المرض ينتشر في أغلب بلدان العالم(1,2,3) •

ينمو فايروس جدري الدجاج في مختلف خلايا الزرع النسيجي مثل خلايا كلية أجنة الدجاج وخلايا ادمة أجنة

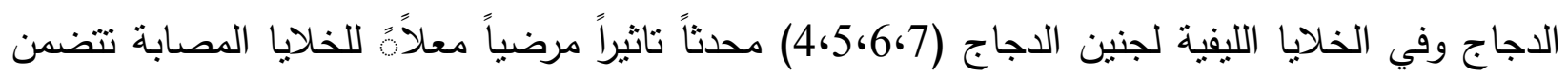
تكور الخلايا و تكون فجوات في الهيولي مع تكون اجسام أنتمالية و نخر و تجمع الخلايا مكونة الخلايا العملاقة (8). تمكن الكثير من الباحثين من ملاحظة التغيرات المرضية المعلة المختلفة في المقاطع النسجية

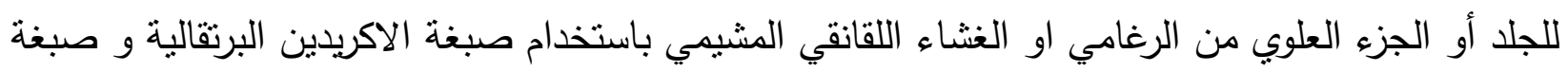

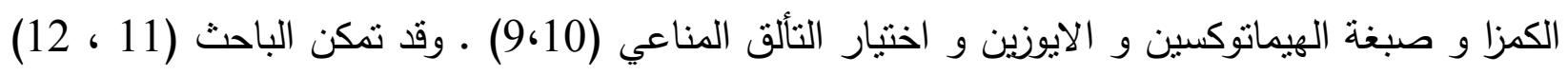

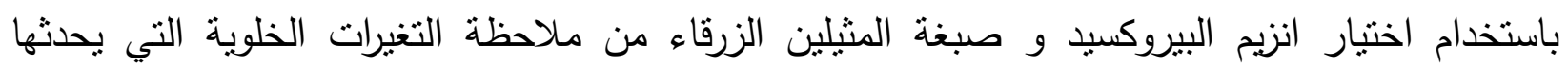
فايروس الجدري في خلايا الغشاء اللقانقي المشيمي والخلايا الطلائية للرغامي.

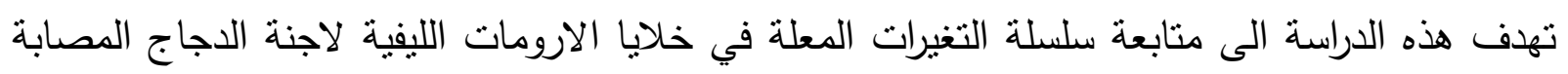
بفايروس جدري الدجاج باستخدام انزيم البيروكسيد و صبغة الاكردين البرتقالية . 


\section{المواد و طرائق العمل}

(الفايروس

استخدم فيروس جدري الدجاج المعزول محلياً (13) و ذلك بحقن 0.1 مل من عالق الفيروس في البيض الحاوي على أجنة الدجاج بعمر 12-10 يوم و بطريقة التقطير على الغشاء اللقانقي الششيمي حسب طريقة

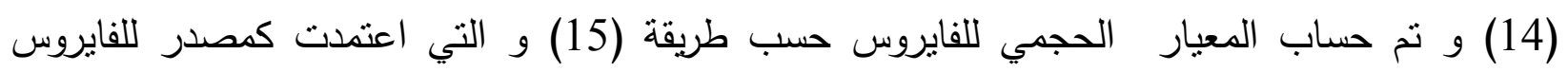
لاحداث الاصابة و كان المعيار الحجمي للفايروس

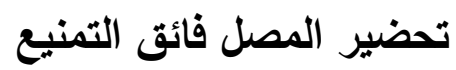

تم تحضير المصل فائق التمنيع على الدجاج و حسب طريقة (16) و قد استخدمت 8 دجاجات من

النوع المحلي بعر 8 أسابيع و قد حقنت في طية الجناح بجرعة 0.1 مل و الحاوية على

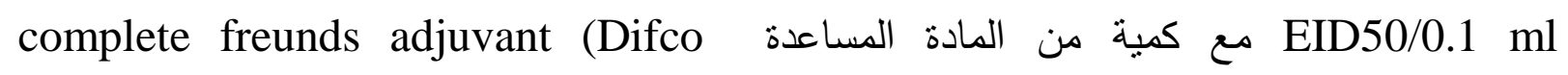
و و اعبدت عملية الحقن كل اسبوع و لاربع مرات و تم جمع الدم من وريد الجناح اسبوعياً و تم فصل المصل من الدم و ابطل فعل المتمما ت غير المتخصصة في حمام مائي بدرجة 56 م

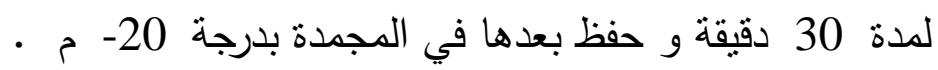
حقن الفايروس في خلايا الزرع النسيجي استخدمت الخلايا الليفية لاجنة الاجاج و ذللك باتباع طريقة (17) لتحضيرها. ثم تخفيف عالق الفايروس بنسبة 10:1 بمحلول الملح الوظيفي (PBS) و حقن 0.1 مل من العالق في خلايا الارومات

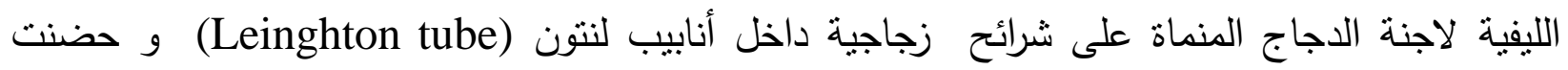
بدرجة 37 م لمدة ساعة لغرض امتزاز الفايروس ثم غسلت بمحلول (PBS) ثم اضيف لها محلول هانكس الحاوي على مصل عجل بقري ومضادات حيوية و حضنت الأنابيب المحقونة بالحاضنة مع ضوابط التجربة و تم اخذ عينتين بعد اختبار انزيم البيروكسيد المناعي غير المباشر بدان استخدم هذا الاختبار باتباع طريقة (16) حيث نم استخراج الثرائح الزجاجية الحاوية على الخلايا

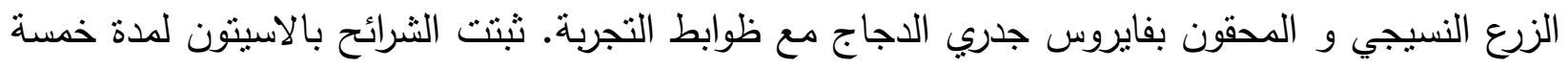
دقائق ثم غسلت بال PBS و جفقت أضيفت لها المصل الفائق التمنيع بنسبة 10:1 وحفظت في حمام مائي

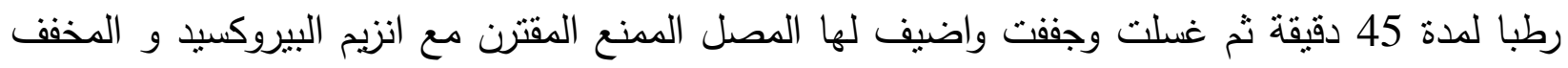

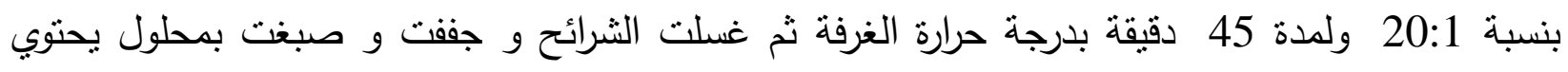
على بيروكسيد الهيدروجين بنسبة 1\% و ايثانول 2\% المشبع بمادة (Orthophsphadimine) 


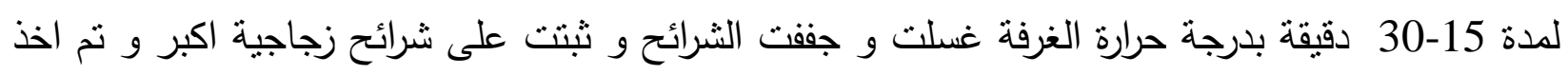

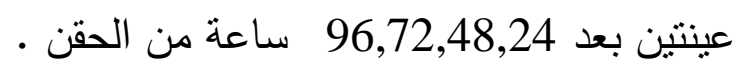
تحضير عينات صبغة الاكريدين البرتقالية

بعد استخراج الثرائح الزجاجية من انابيب لينتون و الحاوية على الخلايا المصابة مع ظوابط التجربة ثم غسلت و ثبتت بمحلول كاروني (Carnoy`s fluid) ثم مررت بالايثانول بتراكيز تنازلية ثم شطفت بمحلول كبريتات المغنيسيوم وو ضعت بعد ذلك بحامض الخليك لمدة دقيقة واحدة و غسلت مرة ثنانية بمحلول كبريتات المغنيسيوم ثم شطفت بالPBS ثم صبغت بمحلول الاكردين البرتقالية لمدة ثلاث دقائق ثم غسلت و جفقت و ثنتت على شرائح زجاجية بمادة لاصقة و فحصت بالمجهر الاعتيادي اذ تم اخذ عينتين بعد 96,72,48,24 ساعة من الحقن .

\section{النتائج}

نتائج الحقن في البيض الحاوي على الاجنة اظهرت الاغشية المحقونة بعالق فايروس جدري الدجاج تاثيراً مرضياً واضحاً اذ لوحظ في اليوم الخامس بعد الحقن تثخن و تورم عام للغشاء اللقانقي المشيمي بعد التمريرة الاولى ـ اما في التمريرات الثانية

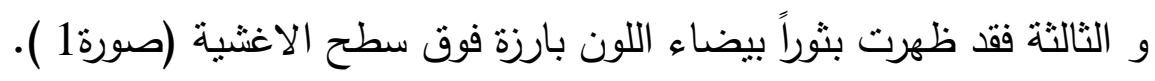

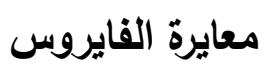

اظهرت نتائج معايرة الفايروس بعد التمريرة الثالثة بان المعيار هو

$$
\text { الذي استخدم في الدراسة . }
$$

نتائج اختبار انزيم البيروكسيد المناعي في لاني

اظهرت نتائج اختبار انزيم البيروكسيد المناعي بعد 24 ساعة من حقن خلايا الارومات الليفية بفايروس جدري الدجاج ظهور تفاعل ايجابي يتمنل بلون قهوائي فاتح يتمركز في هيولي الخلايا المصابة (صورة 2) • و تزداد عتامة الصبغة القهوائية في هيولي الخلايا بعد 48 ساعة من الحقن مع ملاحظة الاجسام الاشتمالية الهيولية ذات اللون القهوائي الداكن التي تعمل على ازاحة النواة الى احد جوانب الخلية ,

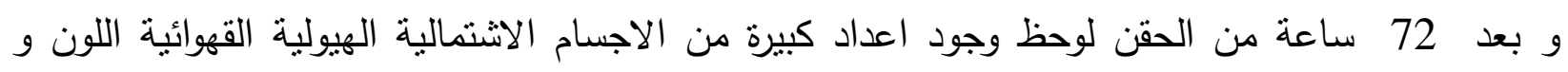

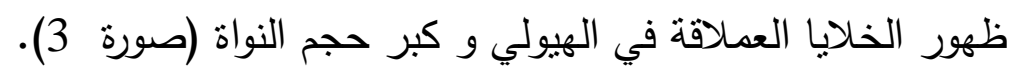
بعد 96 ساعة من الحقن لوحظ وجود فجوات متعددة في هيولي الخلايا المصابة بالقرب من النواة مع كبر حجمها مع ملاحظة التحبب في الهيولي الذي يظهر ذا لون قهوائي خافت. 


\section{نتائج اختبار صبغة الاكردين البرتقالية}

اظهرت نتائج فحص الخلايا المثبتة و المصبوغة بصبغة الاكردين البرتقالية ظهور اجسام محتواة في هيولي الخلايا المصابة ذات اللون الاخضر البراق و تظهر بصورة واضحة اكثر بعد 24 ساعة من الحقن.

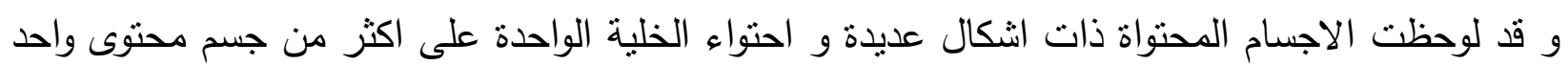

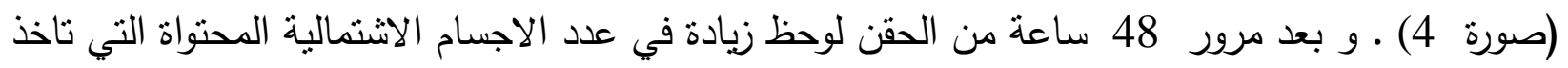

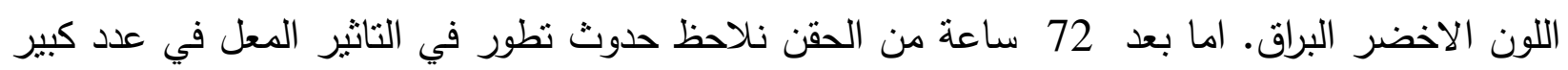
من الخلايا و انويتها الذي يتميز باستدارة بعض الخايا و ظهور الخلايا العملاقة و زيادة في عدد الاجسام الاشتمالية المحتواة و يزداد التاثير الخلوي المعل للفايروس في الخلايا بعد 96 ساعة من الحقن.

\section{المناقشة}

لقد بينت نتائج هذه الدراسة الصفات البايولوجية للفايروس المحقون في أجنة الدجاج النامية اذ ان

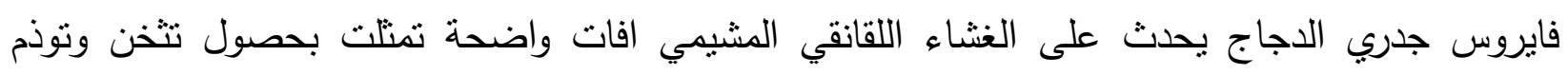
الغثاء في التمريرة الاولى اما في التمريرتين الثانية و الثالثة فقد ظهرت بثور بيضاء مصفرة اللون بعد خمسة

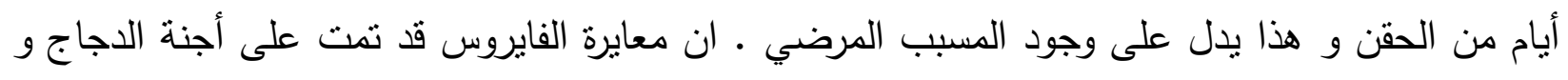

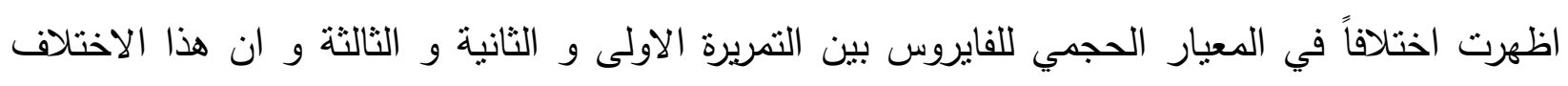

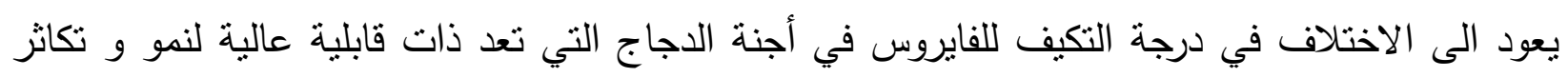

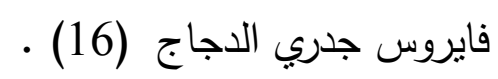
يعد اختبار انزيم البيروكسيد المناعي غير المباشر مع صبغة الاكريدين البرتقالية فحوصات مهمة

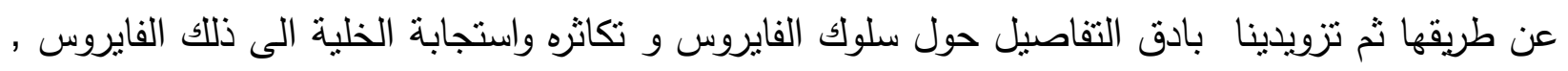

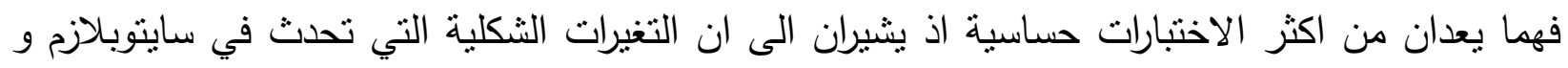

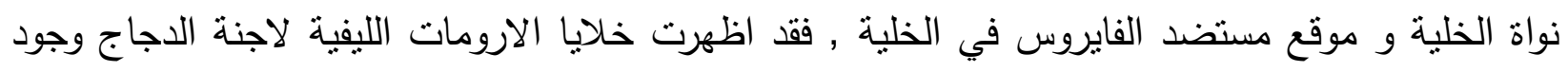
اجسام اثنتالية في هيولي الخلايا بعد 48,24 ساعة من الاصابة و تلونت هذه الاجسام بلون قهوائي فاتح

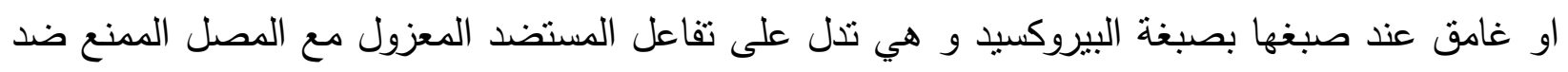

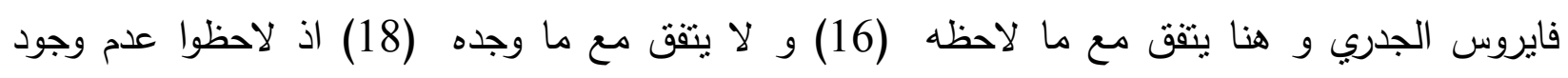

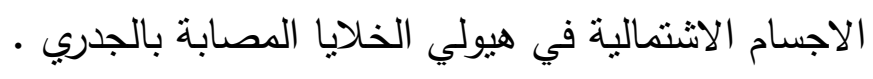

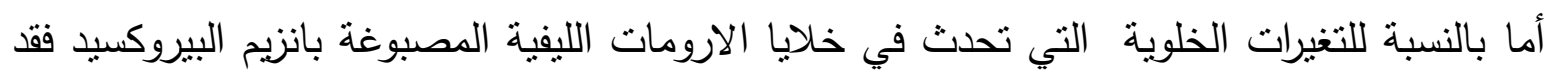
تطابقت مع نتائج اختبار الاكردين البرتقالية حيث لوحظ بعد 24 - 48 ساعة وجود اجسام اشتمالية هيولية

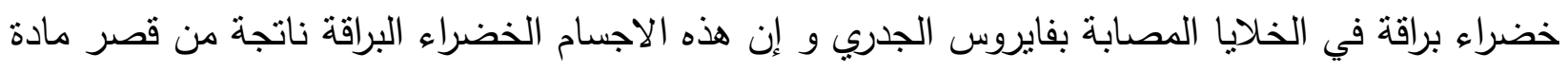

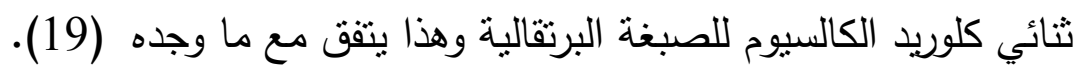


إما بعد 72 ساعة من الاصابة فقد ظهرت زيادة في عدد الاجسام الاتشتمالية القهوائية و الخضراء

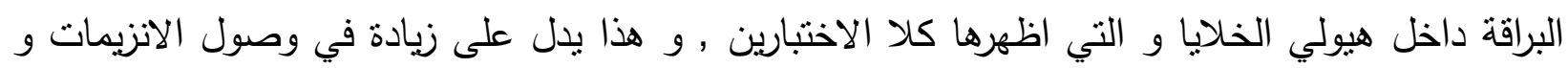
البروتينات التي تتنترك في عملية تكوين الحامض النووي الفايروسي إلى هيولي الخلية و إن هذه الاجسام

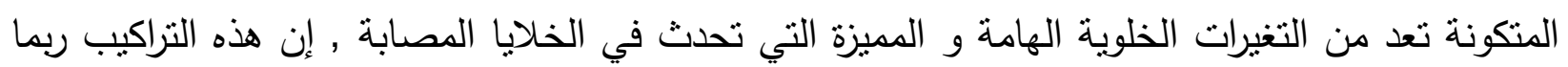

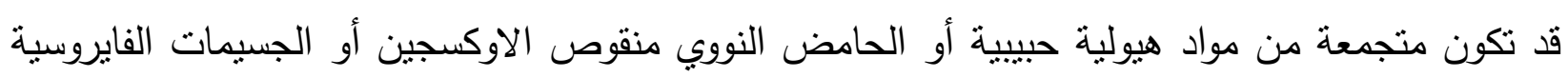
الغير ناضجة وهذا يتفق مع ما وجده (12،12) وفي دراسة امراضية فايروس جدري الدجاج على ملى خلايا الارومات الليفية لاجنة الاجاج بعد 96 ساعة من الاصابة لكلا الاختيارين فان من اهم التغييرات التي

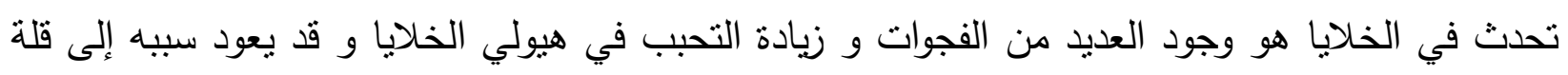

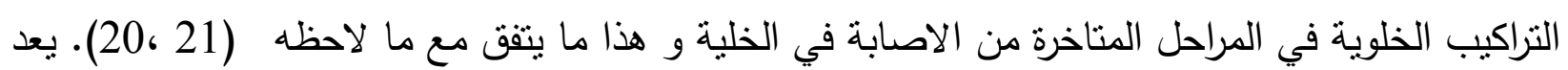

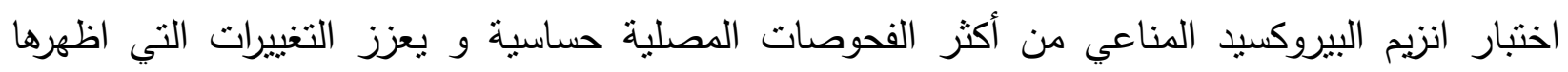

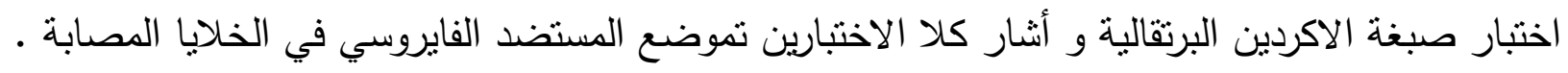

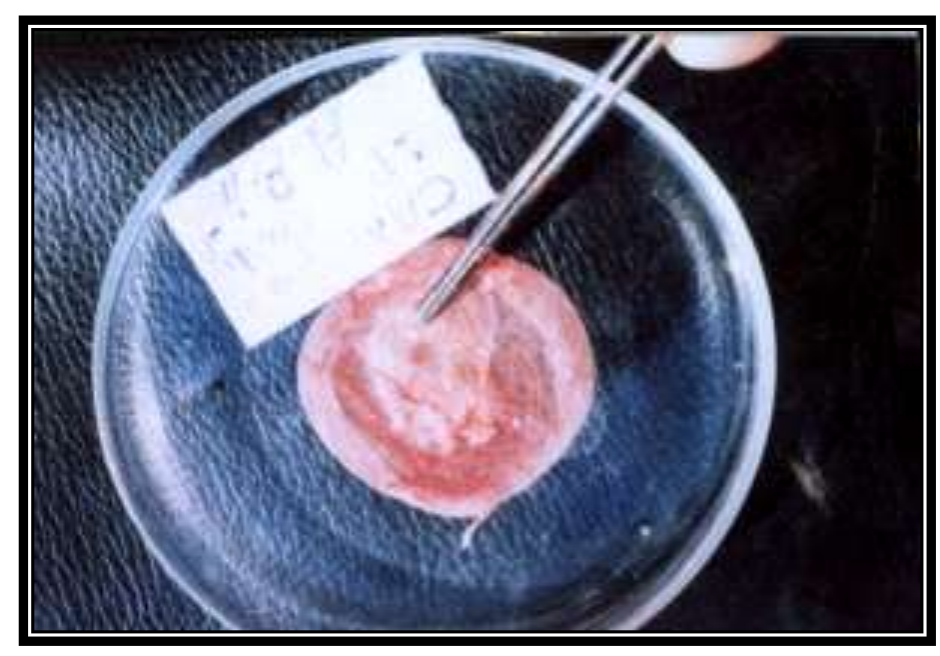

صورة(1) تبين الغثاء اللقانقي المشيمي لاجنة الاجاج في اليوم الخامس بعد الحقن بفايروس جلري

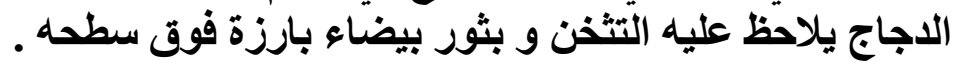




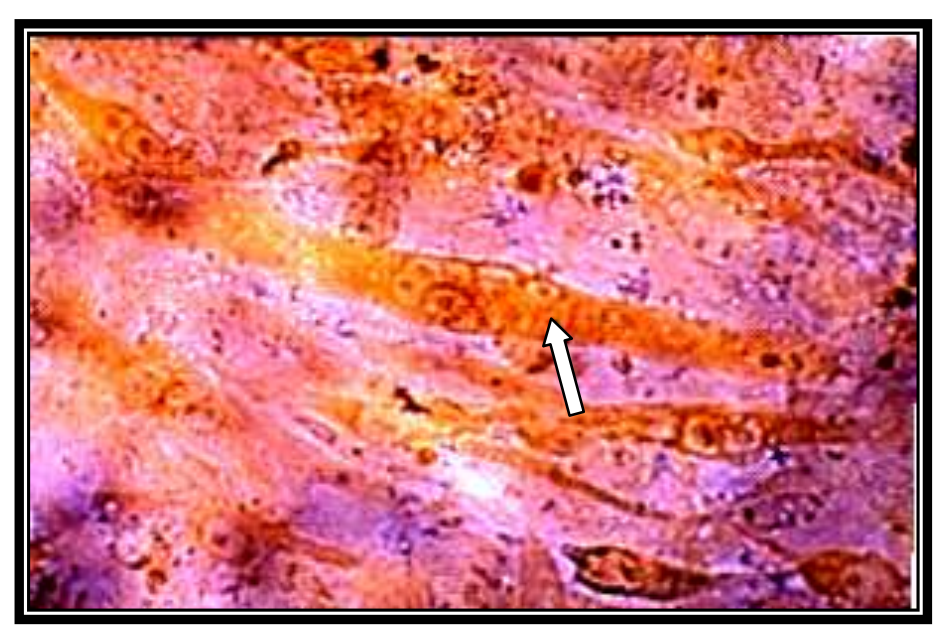

صورة(2 ) تبين وجود الاجسام الاشتمالية الهيولية في خلايا الارومات الليفية لاجنة الاجاج ذات اللون

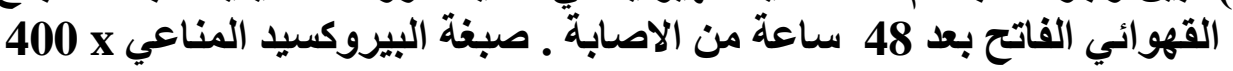

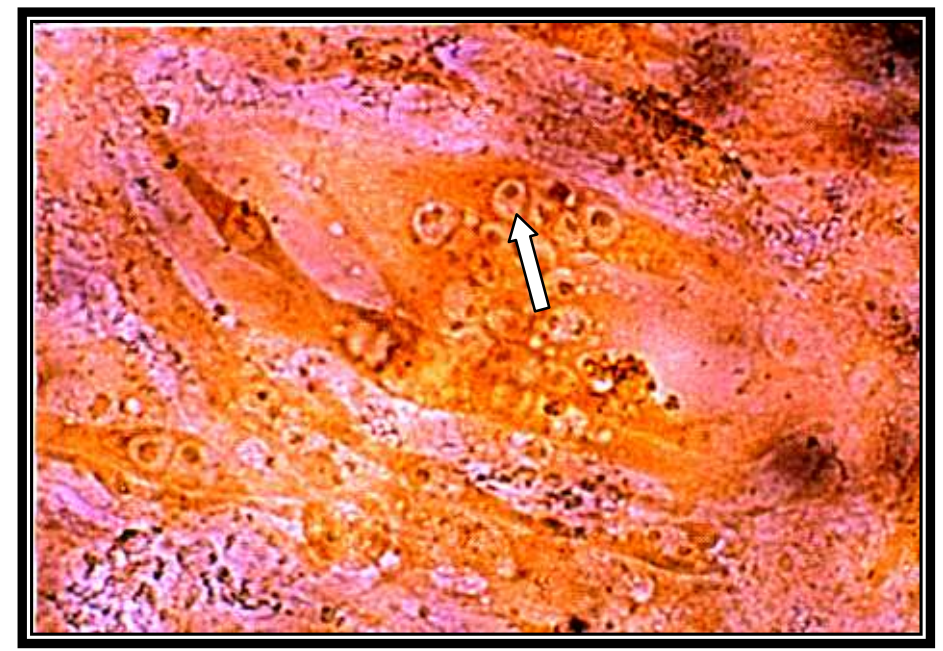

صورة (3) تبين كبر حجم خلايا الارومات الليفية لاجنة الاجاج و زيادة عدد الاجسام الاشتمالية القهوائية

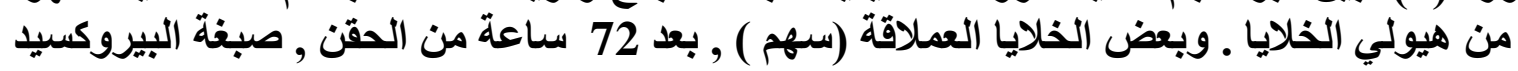
المناعي 400 (

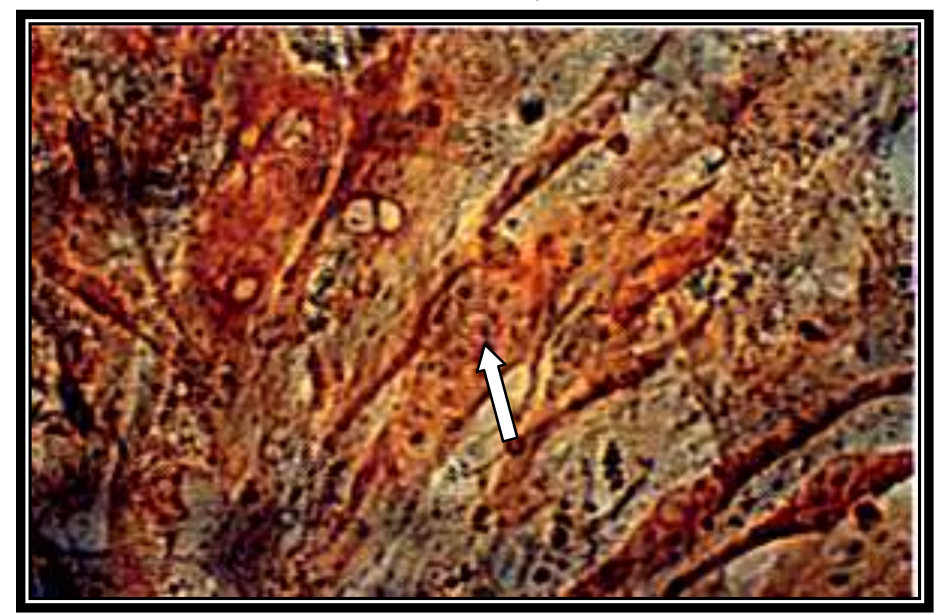

صورة (4 ) تبين اللون الاخضر البراق للاجسام الاثتمالية في هيولي خلايا الارومات الليفية لاجنة الاجاج

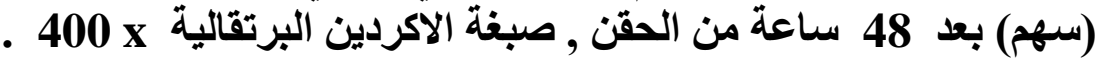




\section{References}

1. FAO, (1992). Animal health year book.

2. Reed, W. M. and Schrader, D. L.(1989). Pathogenicity and Immunogenicity of mynah pox virus in chickens and Bob white quail. Poult. Sci. 68:631-638.

3. Tripathy, D.N. and Cunningham, C.H. (1984). (Cited by Al-Fahad, A., A. (1993). Preparation of fowl pox vaccine in tissue culture. MSc. Thesis, Veterinary Medicine College, Uniersity of Baghdad (Arabic).

4. Tripathy, D.N.; Hanson, L.E. and Killinger, A.H. (1974). Atypical fowl pox in poultry farm in Illinois. Avian Dis. 17: 274-278.

5. EL-Zein, E.; Nehme, S.; Ghoraib, V.; Hasbani, S. and Toth, B. (1974). Preparation of fowl pox vaccine on chicken. Embryo-dermis cell Culture. Avian Dis. 18:495-504.

6. Silim, A.; EL-Azhary, M. A. Y. and Roy, R. S. (1982). A simple technique for preparation of chicken embryo skin cell cultures inoculated with fowl pox virus. 26:182-185.

7. Moss, B.; Fields, B. N.; Knipe, N. M.; Chanock, R. M.; Melnick, J. L.; Roizman, B. and Shop, R. E. (1990).Pox viridae and their replication. Virology 2th ed. Raven press. New York. Pp. 2079-2111.

8. Rao, C. V.; Jayaraman, M. S. and Masillamong, R. R. (1978). Laboratory and field trials with cell culture fowl pox vaccine. Indian Vet. J. 55:133-136.

9. Tripathy, D.N. and Reed, W.M. (1997). Pox In: Diseases of Poultry. (Calnek, B.W.; Barres, H.J.; Beard, C.W.; McDongald, L.R. and Saif, Y.M. Eds.). (10th ed. ). Iowa State University Press, Ames. PP.643-659.

10. Bickford, A. A.; Gallina, A. M.; Winterfield, R. W. and Bolte, H. (1971). Studies of an unusual pox infection in Turkeys. Avian Dis. 15: 614-625.

11. AL-Hyali, H. M.(2001 a).Immunoenzyme detection of fowl pox virus cells of chorioallatoic member and treachea. Iraqi. J. Vet. Sci. Vol. 16(1) P.121127

12. AL-Hyali, H. M. (2001 b). Use of Immunoperoxidase and Methylein Blue staining techniques for detection of pathological changes of Fowl pox virus infected Treacheal epithelial cells. Iraqi. J. Vet. Sci. (accepted for publication).

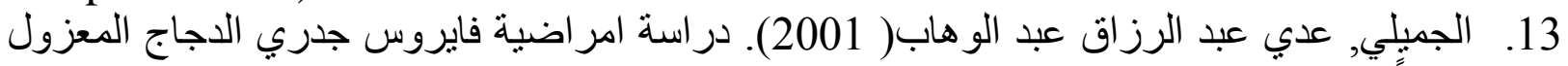

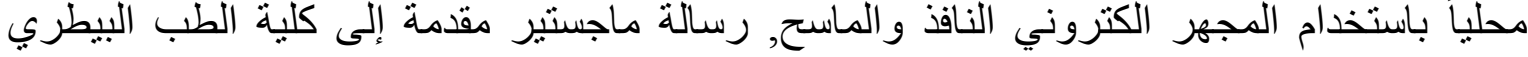

14. Versteege, J. (1985). A colour atlas of Virology. Published by Wolfe Medical. PP.54-63.

15. Reed, L. J.and Muench,A.(1938). Simple method for estimating fifty percent endpoint. AM. J. Hyg. 27:493-497. 
16. Tripathy, D.N. ; Hanson, L.E. and Killinger, A.H. (1973). Immunoperoxidase technique for detection of fowl pox antigen. Avian Dis. 18: 84-90.

17. Hitchner, S. B.; Dornermuch, C. H.; Graham, Purchase, H. and William, J. E. (1980). Isolation and identification of avian pathogens 2nd Ed. Published by the Am. Asso. of Avian pathologists. PP.152-160.

18. Tajiman, M. and Ushijima, T.(1966). Electron microscopy of avian pox viruses with special reference to the significance of inclusionbodies in viral replication. Jop. J. Vet. Sci. 28:107-118.

19. Gluck, L. and Kulovich, M. V. (1964). Histochemical studies of the disturibution of RNA in tissues of the developing chick embryo. Yale. J. Biol. Med. 36:379.

20. Taylor, C. D. (1978). Immunoperoxidase techniqe practical and Theoretical aspects. Arch. Path. Lab. Med. 1:113-114.

21. Chasey, D. (1980).A simple and rapid immunoperoxidase test for detection of virus antigens in tissue culture. Vet. Rec.14:506-407. 